\title{
How Mother and Father Support Affect Youths' Interest in Computer Science
}

\author{
Jody Clarke-Midura \\ Utah State University \\ 2830 Old Main Hill \\ Logan, Utah 43017-6221 \\ jody.clarke@usu.edu
}

\author{
Frederick J. Poole \\ Utah State University \\ 2830 Old Main Hill2 \\ Logan, Utah 43017-6221 \\ frederick.poole@usu.edu
}

\author{
Katarina Pantic \\ Utah State University \\ 2830 Old Main Hill \\ Logan, Utah 43017-6221 \\ katarina.pantic@aggiemail.usu.edu
}

\author{
Chongning Sun \\ Utah State University \\ 2830 Old Main Hill2 \\ Logan, Utah 43017-6221 \\ vincent.sun@aggiemail.usu.edu
}

\author{
Vicki Allan \\ Utah State University \\ 4205 Old Main Hill2 \\ Logan, Utah 43017-6221 \\ vicki.allan@usu.edu
}

\begin{abstract}
Parental support is a predictor of children's career interest and aspirations. However, mother and father support affects youth career choices differently. To understand how perceived mothers' and fathers' support affect career interest in computer science (CS), we developed two path models using both mother and father support gains to predict youths' interest in CS. We hypothesized that perceived father's and mother's support would relate to youths' interest in CS via youths' perception of CS utility value as a mediator. We found that both mother and father support leads to interest in CS. However, father support was found to affect CS interest via the mediator utility-value beliefs. To provide explanations for these differences we used student interview data to explore how participants in our study perceived parental support.
\end{abstract}

\section{CCS CONCEPTS}

- Applied computing $\rightarrow$ Education; Computer-assisted instruction;

\section{KEYWORDS}

Father support, mother support, computer science, career interest, middle school

\section{ACM Reference format:}

Jody Clarke-Midura, Frederick J. Poole, Katarina Pantic, Chongning Sun, and Vicki Allan. 2018. How Mother and Father Support Affect Youths' Interest in Computer Science. In Proceedings of 2018 International Computing Education Research Conference, Espoo, Finland, August 13-15, 2018 (ICER '18), 8 pages.

https://doi.org/10.1145/3230977.3231003

Permission to make digital or hard copies of all or part of this work for personal or classroom use is granted without fee provided that copies are not made or distributed for profit or commercial advantage and that copies bear this notice and the full citation on the first page. Copyrights for components of this work owned by others than ACM must be honored. Abstracting with credit is permitted. To copy otherwise, or republish, to post on servers or to redistribute to lists, requires prior specific permission and/or a fee. Request permissions from permissions@acm.org.

ICER '18, August 13-15, 2018, Espoo, Finland

(C) 2018 Association for Computing Machinery.

ACM ISBN 978-1-4503-5628-2/18/08...\$15.00

https://doi.org/10.1145/3230977.3231003

\section{INTRODUCTION}

Parental support has consistently been found to be a predictor of career interest and aspirations for youth [22, 32, 33, 38]. However, simply investigating parental support as an umbrella construct for both mother's and father's support is problematic because individual parental contributions and their effects are not taken into account. Previous research has found that the effectiveness of parental support on academic behavior depends on the gender of both parent and child $[1,12,33]$. While there is research that shows that mothers and fathers influence career choices differently, there is a dearth of research on how their support affects youth interest in computer science (CS). This is relevant because increasing workforce demands in CS industries have highlighted the need for more research on how to best recruit future computer scientists, particularly female computer scientists, who are currently underrepresented in the field $[2,4,30]$. The purpose of this study was to explore both direct and indirect pathways linking perceived mother and father support to interest in CS, and to investigate any potential differences in these pathways.

According to Eccles' $[10,40]$ expectancy-value theory, academic behaviors, such as performance, perseverance, and choice are directly affected by expectancy and task-value beliefs. In this model, expectancy beliefs refer to one's beliefs about how well they will do in a task, while task-value beliefs refer to the degree in which a) one perceives the task as enjoyable (intrinsic interest), b) the task affirms one's personal values (attainment value), c) one perceives the task as useful (utility value), and d) the cost of engaging in the activity $[10,11]$. Both expectancy and task-value beliefs are said to be influenced by several environmental factors, such as, societal and cultural values, family demographics, and support from teachers, peers, and parents among others. However, of interest in this study is how perceived parental support affects perceptions of CS utility value, and subsequently CS interest. We argue that the relationship between parental support and utility value is particularly important because, as Harackiewicz et al. [19] state, it may be easier for parents to influence perceived utility value than it would be to influence other parts of the task value construct. In other words, by simply having a conversation about the value of CS and the future opportunities afforded by a CS degree, parents 
may be able to improve their child's perception of CS utility value. Changing one's perception of intrinsic interest, attainment value, or self-efficacy, on the other hand, may be much more complex.

For the past three years, we have been investigating the effects of one-week, summer App camps on middle school-aged youths' interest in CS. One of the unique aspects of our camp is that campers are given an android device to build their Apps on and are encouraged to take their phones home to show their app designs to their family members. Through exchanges with campers and parents, we came to understand that the phones may have been acting as a mediator between campers and their parents for conversations about CS as a useful skill and as a career. Such insights sparked an interest in the effect of perceived parental support on campers' perceptions of CS utility value and conversely, on CS interest. However, given prior research on the unique experiences and support that mothers and fathers provide their children with [11], we argue that it is important to investigate these effects for both mother and father independently. In the following section, we will first situate this study in the current literature by reviewing studies that have investigated the effect of CS interventions on middle school participants' interest in CS. In addition, we will review past studies that have examined not only the effects of parental support on career interest, but also how mothers and fathers uniquely influence their child's career choices.

\section{BACKGROUND LITERATURE}

\subsection{Middle School Youth and Computer Science}

Middle school is the developmental level when youth start to make decisions about careers [9, 13, 20]. Consequently, research has shifted toward a focus on how to engage middle school students in CS by using programming environments that are more userfriendly and have the potential to lower the cognitive threshold for novice programmers, such as Scratch [16, 34], Alice [23, 24] and other similar programs. Overall, studies repeatedly found that environments like the ones mentioned above are effective in the acquisition of basic programming skills and concepts [25, 26, 34]. As an example, Meerbaum-Salant, Armoni, and Ben-Ari [28], in their investigation of the effectiveness of Scratch, found that while Scratch was not equally effective for all CS concepts, the program did help middle schoolers learn most of the targeted CS concepts.

Although research has demonstrated the effectiveness of a variety of strategies for increasing middle school-aged youths' understanding of CS concepts, the findings on increasing interest and attitudes towards CS have been mixed. There is some evidence to show that storytelling environments raised the interest of female middle schoolers in CS $[23,24]$. In our own research, we found that mentor relatability of near-peer mentors significantly predicted both self-efficacy and interest gains of middle school campers [7]. Other studies, however, provide different results. Mouza et al. [29], for example, investigated both the effectiveness of an after-school CS program using Scratch taught by undergraduate CS majors and the impact of the program on student affect towards CS. The researchers found that while middle schoolers gained knowledge related to CS concepts, there were no significant gains in their feelings and attitudes towards CS. The authors did acknowledge, however, that this was probably because the participants all volunteered to attend the program and thus already held favorable perceptions of CS. Huang et al. [21] attempted to use Plushbots to motivate and increase positive attitudes in middle school students towards CS. Unfortunately, the researchers did not find any growth in student interest or attitudes towards CS. Similarly, while studying a 7-week CS introductory course designed for middle schoolers, Grover, Pea and Cooper [18] did not find a change in student affect towards CS. However, it should be noted that they did report significant gains in participants' knowledge of CS concepts.

One strategy for increasing youth interest in CS may be to elicit parental involvement. Harackiewicz et al. [19] conducted a 15-month intervention in which educational brochures about the importance of mathematics and science in everyday life as well as how to relate such information to children were sent home to parents. They found that children whose parents received the brochures were more likely to take advanced STEM courses in high school. Furthermore, they conducted a path analysis which illustrated that their intervention was associated with an increase in parental STEM utility value beliefs, which was then associated with an increase in student STEM utility value beliefs. They also found that their intervention was associated with more conversations between parents and their children about STEM related careers. The number of conversations reported were associated with student perception of STEM utility value beliefs. These findings suggest that parents play a role in broadening and increasing youth participation in CS related activities. Few studies have looked at how CS interventions affect the relationship between parent and child, particularly the perceptions a child has of parental support when they started to show an interest in CS. Understanding this dynamic is important because, as the following literature will illustrate, perceived parental support and involvement predict youth career choices and interests.

\subsection{Parental Support and Career Interest}

Several studies in STEM related subjects have investigated the impact of parental support on student career interest and learning experiences [22, 32, 33, 38]. Not only was parental encouragement in math and science found to significantly influence student learning experiences [15], it has also been reported that parental support increased career decidedness and career self-efficacy, which subsequently increased persistence in the area of study [36]. According to Turner and Lapan [38], parent support accounted for as much as $29-43 \%$ of the total unique variance in vocational self-efficacy of middle school adolescents. Alliman-Brisset, Turner, and Skovholt [1] further found that the primary predictor of girls' self-efficacy was their parents' emotional support, while for boys it was their career-related modeling. In terms of CS, Denner [9] found that parental support was significantly associated with higher utility value beliefs which was significantly associated with an increase in computing interest. However, it should be noted that such studies have generally examined parental support as one construct combining both mother and father measures. This is problematic given that mother and father support may be perceived and/or manifested differently. The following section reviews literature concerning differences between mother and father support. 


\subsection{Differences in mother support and father support}

Research on the different effects of mother and father support in relation to career aspirations have also been somewhat conflicting. Some studies, for example, seem to suggest that fathers are more important for influencing interest in technical careers and mothers are more important for more social-oriented careers. Gates [17] found that women who studied engineering reported their fathers as influencing their decision $(20.1 \%)$ more than women who studied education (11.0\%). However, the percentage of participants who reported their mothers as influential in their career decision making process was similar for both women who studied engineering $(19.4 \%)$ and those who studied education (18.1\%). Simpson [37] concluded that mothers' influence significantly affected the pursuit of public service degrees, whereas fathers' influence affected the pursuit of a technical degree.

However, other studies reported that mothers are more important regardless of career choice. Otto [31], for example, found that youth went to their mothers more often than their fathers for career advice. Similarly, Bahar and Adiguzel [3] found that mothers were more influential than fathers in developing career aspiration in youth. This may be due to the fact that mothers were also found to be more intensely involved and in a more concrete manner when it comes to career-related plans, as found by Palos and Drobot [33]. Given the importance of parental support for youth interest development and the potential different effects found between mother and father support on youth interest, we set out to understand how perceived parental support influenced camper gains in perceived CS utility value and interest in CS. In the following section, we provide a description of the app camps in which the data was collected. In addition, we highlight key areas that we believe may have had an impact on parents' involvement in the campers' CS interest, and also the campers' perception of parental support.

\section{APP CAMPS}

During the summer of 2016, we ran three camps on learning how to program using MIT App Inventor for middle school aged youth. Each camp ran for five days, three hours per day (15 hours total). During this time, campers designed and programmed 9 apps. For a full description of the camp and programming activities please see [6]. Campers worked at their own computer and were provided with an android device to use and take home during the camp. Support in these camps was primarily provided by high schoolers who served as near-peer mentors. Keeping the literature in mind, we designed certain activities we thought would have an impact on the campers and their perceptions of parental support. These activities and design choices include the following:

- We let campers take their android device home each night to share designs with family members, or continue working on their apps, which most campers did.

- We showed videos that provided information about what it was like working in the CS industry.

- The Dean of the College of Engineering and CS, who was female, came in and spoke to the campers about the benefits of working in CS and being able to solve world problems.
We believed that by allowing campers to take home their devices, both camper interest in CS and parental interest in their child's apps would become more salient. In other words, by having an artifact (the android device) to illustrate what was accomplished in the camp, the campers and parents have a starting point for conversing about CS as an interest and potentially as a career. Artifacts, both material and conceptual, have long been known to regulate human interactions in addition to mediating human psychological processes [8]. In addition, we believed that by providing more information about CS opportunities via videos and the Dean talk, we would again provide talking points for the campers to engage in with their parents. Considering these ideas, we make three hypotheses about the effect of our camp in the next section.

\section{HYPOTHESES}

This study was interested in exploring the relationship between parental support, CS utility-value perceptions, and interest in CS for further learning or as a career. With these goals in mind, we formulated the following hypotheses:

Hypothesis 1: We will find significant changes in campers' perception of parental support, interest in CS, and CS utility-value beliefs.

Hypothesis 2: A positive association will be found between increases in perceptions of parental support, gains in interest in CS, and gains in CS utility-value beliefs.

Hypothesis 3: Perceived mother and father support will both manifest itself and influence campers' interest in CS differently.

\section{METHODS}

\subsection{Participants}

All the participants in this sample volunteered to attend our camp and came from a rural area in the Intermountain West of the United States. We advertized our camp at local schools and through organizations focused on youth (e.g. 4-H). Our sample consisted of ninety-two youth (46 males and 46 females) aged nine through thirteen $(M=11.6)$.

\subsection{Data Collection Procedures}

Data for this study came from two sources: surveys and interviews. Campers completed a survey on their interest and affect towards $\mathrm{CS}$ and programming prior to the camp on the first day (pre-) and then again on the last day of camp (post-). Surveys were administered online via Qualtrics survey software. A description of survey design is provided below in the Measures section. In addition to surveys, nineteen campers (4 males, 15 females) across the three camps were randomly selected to be interviewed on the first and last day of camp. Due to limited time and resources, we were not able to interview all the campers. Interview protocols focused on interest, self-efficacy, perceived support, and camp experience. All interviews were audio recorded and transcribed verbatim.

\subsection{Measures}

The survey (aka Affect Survey) was adapted from several established STEM (science, technology, engineering, and mathematics) affect self-report scales, including Fennema-Sherman Mathematics 
Attitude Scale [14], Carrico and Tendhar [5] engineering career choice survey, Vekiri et al. [39] ICT attitude survey, Denner [9] technical curiosity scale, and McLachlan ICT Survey [27]. All items were modified to focus on computer science. The items measured perceived father and mother support in computing, general technical curiosity, goals in seeking a computer science related college degree, self-efficacy and interest in computing, value beliefs toward computing, and outcome expectations for working in a CS related field. All questions were measured on six-point Likert scales (1 = Entirely Disagree, 6 = Entirely Agree). This study was primarily interested in the effect of parental support on interest and as a result only four of the constructs were used for data analysis. Finally, in addition to affect questions, the pre-survey also asked background information such as age, father's highest degree, and mother's highest degree.

\subsection{Constructs of Interest}

For this paper, there were four constructs of interest: interest in CS, value beliefs, perceived mother/father support and mother/father highest education. The term interest refers to what an individual likes and dislikes, as associated with specific tasks, activities, or objects [5]. Utility-value refers to campers' beliefs about the current and future usefulness of the task [39]. Finally, perception of parental support refers to campers' perception of their mothers or fathers' interest, encouragement, and confidence in their CS ability It also includes the campers' perception of their mother's or fathers' example as an individual interest in, confidence of, and awareness of the importance of computing [14].

\section{RESULTS}

Our first hypothesis states that the camp would cause an increase in camper perceptions of father and mother support, interest in CS, and CS utility-value beliefs. We made this hypothesis based on two camp designs. First, in our camp we encouraged campers to take their android devices home and continue to work on their apps. Second, we provided situations for campers to learn about CS opportunities. We believed that both of these strategies would increase either parental involvement in the campers' interest and/or camper perceptions of parental support.

\subsection{Wilcoxon Signed-rank Test}

Many of the campers reported high scores on all of our constructs of interest in the pre-survey (see table 1). This not only presented a ceiling effect problem, but also resulted in skewed data. Therefore, we used a nonparametric test, the Wilcoxon signed-rank test to determine if there were significant differences in our constructs of interest from pre- to post-intervention.

As Table 1 shows, we only found a significant gain in the perception of mother support and CS interest after the camp. Given that our campers started with a median of 5.40 on utility-value beliefs and 5.00 on father support, it is not surprising that we did not find significant gains for these constructs. The boxplots in Figure 1 illustrate that although there may not have been a significant growth in parental support, there was enough variance to warrant further exploration. Our next hypothesis investigates the effect of these changes in perception of parental support on interest in CS.

\begin{tabular}{lllllllll}
\hline & \multicolumn{3}{c}{ Pre } & \multicolumn{7}{c}{ Post } \\
\hline & Med & SD & $\alpha$ & Med & SD & $\alpha$ & $\begin{array}{l}\text { Wilcoxon } \\
\text { Test }(\mathrm{Z})\end{array}$ & df \\
Interest & 5.00 & 0.96 & 0.88 & 5.20 & 1.01 & 0.93 & $2.51^{* *}$ & 83 \\
Value Beliefs & 5.40 & 0.88 & 0.84 & 5.20 & 0.91 & 0.89 & 0.88 & 83 \\
Father Support & 5.00 & 0.98 & 0.86 & 5.00 & 0.90 & 0.79 & 1.42 & 77 \\
Mother Support & 5.00 & 0.95 & 0.82 & 5.20 & 0.87 & 0.85 & $2.98^{* *}$ & 80 \\
\hline
\end{tabular}

Table 1: Wilcoxon-Signed Rank Test

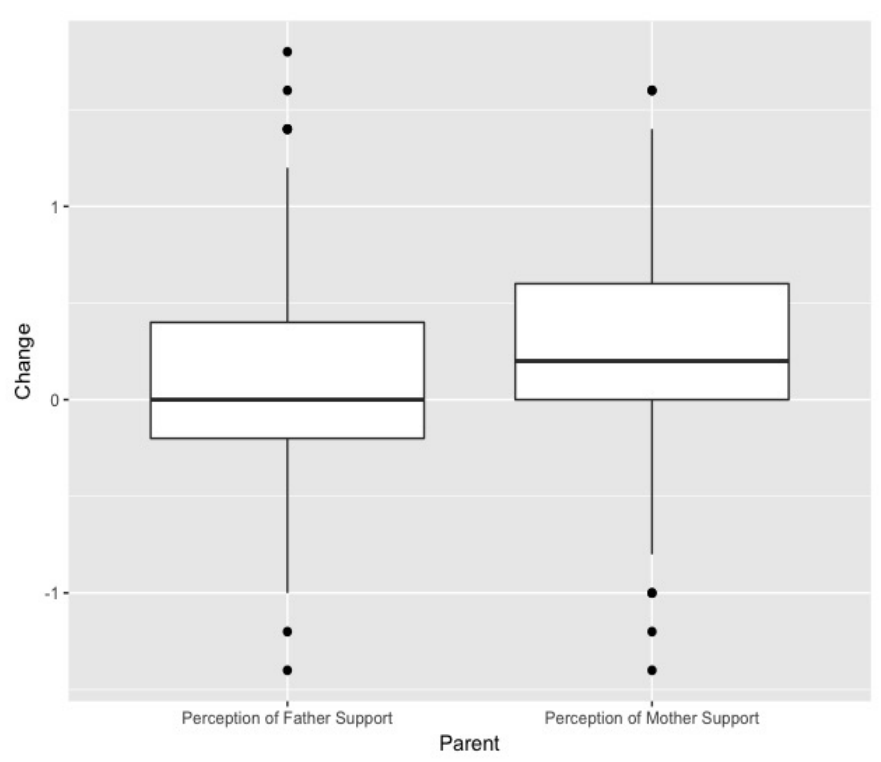

Figure 1: Perception of Father and Mother Support Change. Note: Boxplots illustrate distribution of change scores. All change scores are on a 1-6 scale and were calculated by subtracting the pre-scores from the post-scores.

Previous literature has found that father and mother support are positively associated with career interest development [32, 38]. However it should be noted that some studies have found that the influence of mother and father support on career interest affects sons and daughters differently [.e.g. 1], especially when the type of career is considered (e.g. social, technical) [.e.g. 37]. Given these findings, we hypothesized that gains in parental support would also be associated with gains in CS interest. To explore our second hypothesis, we first conducted a correlation analysis with our constructs of interest. Figure 2 shows that all constructs were significantly correlated. Please note that for this analysis we used gain scores as our dependent variables because we were interested in exploring what factors predicted these changes.

Next, we conducted a step-wise multiple linear regression analyses in R [35]. To ensure that there were no violations of assumptions of normality, linearity, multicollinearity, and homoscedasticity, preliminary analyses were conducted. In the first step, gender of the camper was added to control for gender differences. In step two, utility-value beliefs, which has been shown to be a strong predictor 


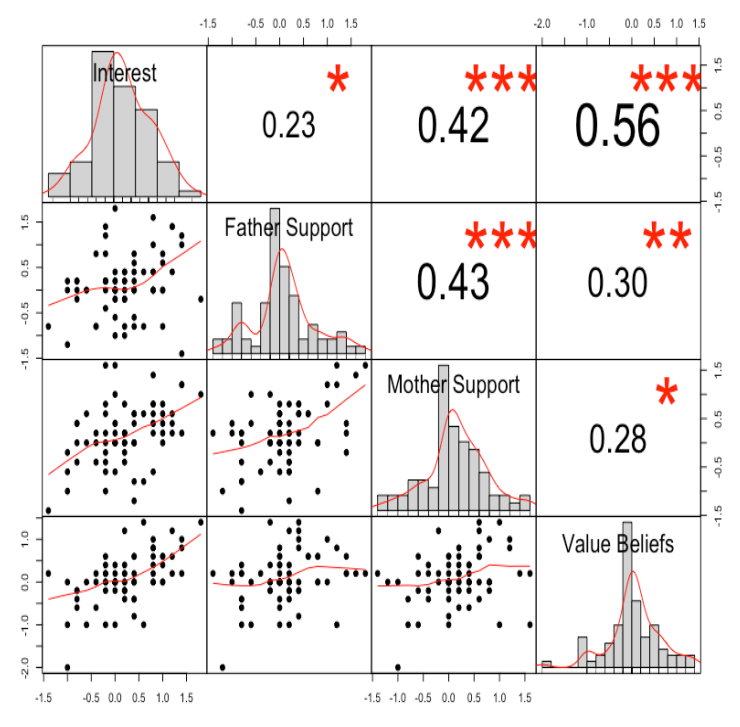

Figure 2: Correlation Matrix with Bivariate Scatter Plots Note: Variables presented in this figure are gain scores.

of career interest was added. Then, in step three both mother and father support were added to the model. Finally, we ran an ANOVA to determine if the added variables in each step significantly increased the amount of variance explained by the model. As can be seen in Figure 3, both Model 2 and Model 3 explained more variance than the previous models. The final model with both mother and father support explains more variance in CS Interest gain than the second model with just gender and utility-value beliefs $\left(\chi^{2}(2)=2.58\right.$, $\mathrm{p}=.01)$ and is significant $(F(4,71)=12.12, p<.001)$, with an $R^{2}$ of .372. In other words, the addition of the mother and father support variables accounted for approximately $7.2 \%$ more variance than was accounted for by Model 2 . However, it should be noted that in this final model, father support was not significant. This will be discussed further when looking at our third hypothesis. For mother support gain, which was significant, a one-unit increase in gains in perception of mother support on a 6-point scale is associated with a .337 increase in CS interest. In other words, as campers' perceptions of mother support increases so does their interest in CS.

Although father support was not significant in our third model ( see figure 3), research suggests that it is. Furthermore, given our third hypothesis that mother and father support will be perceived differently and thus have unique impacts on interest, we decided to use a path analysis to further explore the potential mediating effect of utility value for father and mother support on CS interest.

\subsection{Path Analyses}

To investigate our third hypothesis, we created two path models with mother and father support. Only those participants who completed pre- and post-surveys were included in the analysis. No univariate or multivariate outliers were detected. The univariate and multivariate linearity assumption was tested and satisfied. Gain

\begin{tabular}{|c|c|c|c|}
\hline \multicolumn{4}{|c|}{ Interest Gain Model } \\
\hline & \multicolumn{3}{|c|}{ Dependent variable: } \\
\hline & \multicolumn{3}{|c|}{ Interest Gain } \\
\hline & (1) & (2) & (3) \\
\hline Gender (Male) & $\begin{array}{c}-0.000 \\
(-0.295,0.295)\end{array}$ & $\begin{array}{c}0.102 \\
(-0.144,0.348)\end{array}$ & $\begin{array}{c}0.131 \\
(-0.106,0.368)\end{array}$ \\
\hline Utility Value Gain & & $\begin{array}{c}0.646^{* * *} \\
(0.432,0.859)\end{array}$ & $\begin{array}{c}0.564^{* * *} \\
(0.349,0.779)\end{array}$ \\
\hline Mother Support Gain & & & $\begin{array}{c}0.337^{* *} \\
(0.117,0.558)\end{array}$ \\
\hline Father Support Gain & & & $\begin{array}{c}-0.035 \\
(-0.240,0.171)\end{array}$ \\
\hline Constant & $\begin{array}{c}0.211 \\
(0.002,0.419)\end{array}$ & $\begin{array}{c}0.109 \\
(-0.067,0.284)\end{array}$ & $\begin{array}{c}0.048 \\
(-0.126,0.221)\end{array}$ \\
\hline Model Fit (ChiSq) & & $.000 * * *$ & $.010^{*}$ \\
\hline Observations & 76 & 76 & 76 \\
\hline $\mathrm{R}^{2}$ & 0.000 & 0.325 & 0.406 \\
\hline Adjusted $\mathrm{R}^{2}$ & -0.014 & 0.306 & 0.372 \\
\hline Residual Std. Error & $0.656(\mathrm{df}=74)$ & $0.543(\mathrm{df}=73)$ & $0.516(\mathrm{df}=71)$ \\
\hline F Statistic & $0.000(\mathrm{df}=1 ; 74)$ & $7.558^{* * *}(\mathrm{df}=2 ; 73$ & $2.124^{* * *}(\mathrm{df}=4 ; 71)$ \\
\hline
\end{tabular}

Figure 3: Multiple Regression Output

\begin{tabular}{llllll}
\hline Outcome & Determinant & Unstd. & SE & $p$ & std. \\
\hline Mother Support & Utility Gain & .303 & .118 & $0.10^{*}$ & .290 \\
Utility Gain & Interest & .498 & .092 & $.000^{*}$ & .484 \\
Mother Education & Utility Gain & .049 & .055 & .364 & .096 \\
Mother Support & Interest & .309 & .096 & $.000^{*}$ & .484 \\
\hline
\end{tabular}

Table 2: Path Analysis Output: Mother Support Model

scores from pre- to post-surveys were again used for this data analysis. In this path analysis, we examined the mediating effect of utility value for both mother and father support gains. These path analyses were conducted using maximum likelihood estimation (MLE) and were conducted in R [35].

6.2.1 Father Support Model. Results of the path analysis for the father support model with all participants included found that the model fit the data well according to multiple indices of fit: $\chi^{2}(1)$ $=0.016, p=.899, \mathrm{RMSEA}=.000, \mathrm{SRMR}=.003, \mathrm{CFI}=1.00, \mathrm{TLI}=$ 1.13. Each of the individual paths were significant and in the hypothesized direction with the exception of the path between father support and CS interest, $p=.533$ and father's highest education and utility value, $p=.174$.

6.2.2 Mother Support Model. Results of the path analysis for mother support with all participants found that the model fit the data well according to multiple indices of fit: $\chi^{2}(1)=0.931, p=$ $.335, \mathrm{RMSEA}=.000, \mathrm{SRMR}=.022, \mathrm{CFI}=1.00, \mathrm{TLI}=1.00$. Each of the individual paths were significant and in the hypothesized direction with the exception of the path between mother's highest education and utility value gain, $p=.364$.

The path analyses showed a difference between mother and father support in that mother support had both a direct and indirect effect on gains in CS interest, whereas gains in father support only 


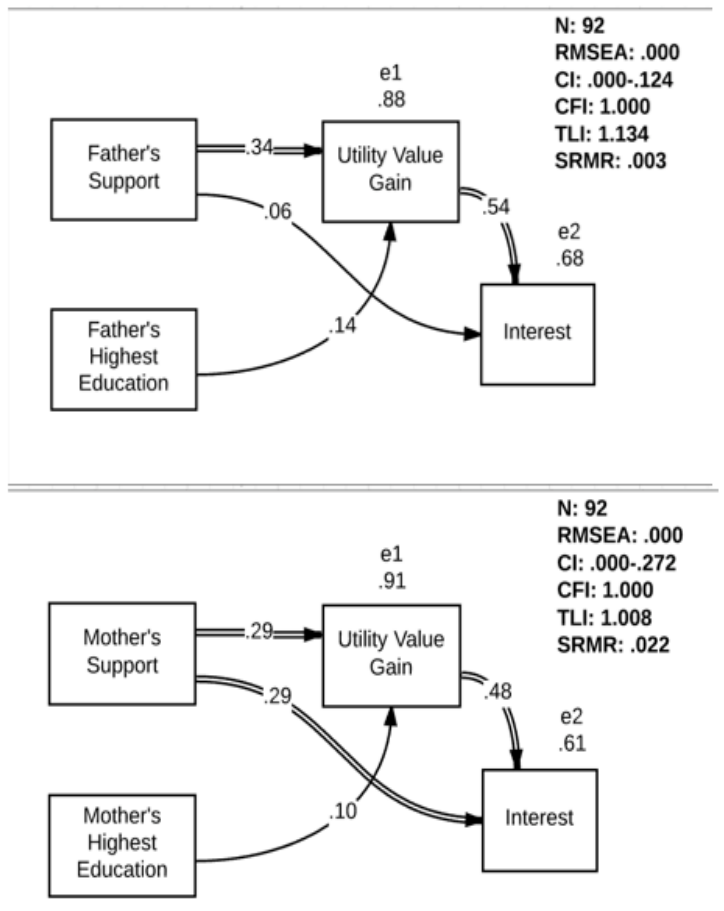

Figure 4: Mother and Father Support Gain Models

Note: All variables, with the exception of highest education, are gain scores. Double lines indicate significant relationships.

\begin{tabular}{llllll}
\hline Outcome & Determinant & Unstd. & SE & $p$ & std. \\
\hline Father Support & Utility Gain & .326 & .107 & $0.002^{*}$ & .341 \\
Utility Gain & Interest & .561 & .098 & $.000^{*}$ & .545 \\
Father Education & Utility Gain & .069 & .051 & .174 & .141 \\
Father Support & Interest & .059 & .095 & .533 & .060 \\
\hline
\end{tabular}

Table 3: Path Analysis Output: Father Support Model

had an indirect effect via utility value on gains in CS Interest. In other words, gains in camper perception of father support were shown to be significantly associated with gains in utility-value beliefs, which was subsequently associated with gains in CS interest. However, gains in perceived mother support are significantly associated with gains in both utility-value beliefs and CS interest directly. To further understand why this difference exists, we looked to the interview data concerning camper relationships with their parents.

\subsection{Interview Data}

Our third hypothesis stated that parental support would both be perceived differently by campers and, subsequently, affect camper interest in CS differently. In our path analyses, we found that gains in mother support had a direct influence on gains in camper CS interest whereas gains in father support had an indirect effect on
CS interest gains via gains in utility-value beliefs. We conducted a thematic analysis of nineteen interviews with campers from the three camps to explore how and if camper perceptions of parental support might provide insight into how mother and father support was manifested. Furthermore, we were interested to see if such differences in manifestations could explain the differences found in our path analyses. The thematic analysis revealed four themes from the data: parent as an instructor, parent as a model, emotional/administrative support, and co-learning.

6.3.1 Parent as Instructor. Of the 19 participants interviewed, five campers noted examples of their fathers providing support in the form of instruction, whereas no campers reported such examples of their mothers. In these examples, campers typically reported that their father taught them a programming language or showed them how to build a website or a game. When asked to describe what made her father a computer scientist, a young female participant said, "he makes a lot of websites for his job... and he's pretty... smart... he taught me how to program stuff." This camper went on to explain how her father had helped her make a gummy bear themed website. Four other participants reported that their fathers taught them a programming language such as: Java, Scratch and HTML.

6.3.2 Parent as Model. Of the 19 participants interviewed, six campers noted examples of their fathers providing support in the form of modeling, whereas no campers reported their mothers as a model. In these examples, campers usually reported watching or being aware of their fathers' work involving CS. For example, one female camper noted that when her father programs "he seems like he's having a fun time doing it, so I thought it would be a fun thing to do." Another camper explained how her father influenced her interest in CS by saying, "just like watching him do all that stuff it really interested me because I mean, it requires like, like memory and stuff, and like, you type a lot of stuff if you want to do coding by hand." Other participants simply stated that they see their father programming "all the time" or that they went to their father's work place and "just saw what they did and I thought it was cool." Finally, one participant also noted that she could see herself going into the CS industry, when asked why she said, "my dad is a computer scientist and I know how much it pays."

6.3.3 Emotional and Administrative Support. In terms of emotional and administrative support, ten of the 19 participants reported examples of their mothers providing emotional/administrative support, whereas only four participants reported such support from their fathers. Examples of emotional and administrative support included expressing an interest in the child's interest, driving the child to and from camps, and encouraging the child to learn more. For example, one female camper noted, "my mom mostly gets me involved with the things that can help me learn more." This camper went on to confirm that her mother signed her up for our camp. When asked how her family has shown interest in what she's doing, another camper said, "my mom took me here and every time I come back to the car, she's like what did you do today? I just hand her the phone and I'm like, Go crazy! and she's like Oh yea, this is, this is fun." Similarly, four other campers noted that their mothers asked to see what they did each day after the camp. A few campers 
also noted that their fathers provided emotional support in the form of showing interest. One female camper said, "my dad kind of encouraged me to learn a little bit more about computers because I'm the most electronic one in the family." Three other campers noted that their father thought their apps were cool.

6.3.4 Parent as a Co-Learner. In the parent as a co-learner theme, two participants noted that their mother acted as a co-learner, whereas no campers reported their fathers in such roles. Parent as a co-learner refers to instances where the parent learns with their child. For example, when one female camper was asked how her mother influenced her perception of computer science she said:

well my mom she came with me to the university thing, and she was doing really good at the robot thing, then I tried at it and I didn't do too well and that just made me want to do better so that I could be as good as her.

Another camper, when commenting on his past programming experience, recalled learning Scratch with his mother, "like my mom, me and my mom did like, there's like a notebook that you look at and it teaches you stuff... like scratch stuff."

Findings from the interviews seem to suggest that campers saw their mothers as more active participants in their interests. More mothers were reported as encouraging involvement in the CS activities, as facilitating the logistics of such activities, as showing interest in camper achievements, and in some cases as participating in the learning. On the other hand, many campers reported father support as a model. In other words, many campers simply noted how observing their fathers working in the CS industry or having fun with CS-related activities motivated them to learn more. When campers did report father involvement, it was in the role of an instructor. This may explain why fathers only had an indirect effect on CS interest via camper utility-value beliefs. In other words, by seeing their fathers use CS in everyday life, and by receiving hands-on instruction in computing, these campers may be more likely to see the value in CS than other campers. We will further expand on these findings in the following section.

\section{DISCUSSION}

In this study, we set out to explore the relationship between perceived parental support and youth interest in CS. Specifically, we were interested in investigating how gains in perception of mother and father support affected gains in CS utility-value beliefs and in terest. To that end, we hypothesized that mother and father support would affect camper perceptions of CS differently. We found that gains in mother support was significantly associated with gains in both CS utility-value beliefs and interest. Interview data suggest that this may have been due to mothers' active involvement in developing their child's interest by showing their interest in their child's work, encouraging their child to participate in CS activities, and providing logistical support, which is consistent with findings from the Palos and Drobot [33] study. For gains in father support, we found a significant association with gains in CS utility-value beliefs but not in interest. However, gains in utility-value beliefs were significantly associated with gains in CS interest which means that gains in father support had an indirect effect on CS interest but was mediated by gains in CS utility-value beliefs. Interview data suggest that fathers may have had a direct influence on utility-value beliefs due to camper perceptions of father support and influence. Several campers reported being aware of their fathers working on $\mathrm{CS}$ related projects or working in a CS career, which may explain the indirect connection between these two constructs. In addition, some of the campers noted that their father had taught them aspects of a programming language. This may have contributed to utility-value beliefs as it provided an opportunity for campers to see what is possible with CS skills.

This project and our hypotheses were originally inspired by our beliefs that our camps were promoting parental involvement in our campers CS interest. Some earlier research concluded that parental involvement can be effective in fostering children's career planning if the parents are supported by a structured program [32]. To provide structure for the children as well as their parents, we not only provided our campers with information regarding potential CS careers, but we also allowed the campers to take their android devices home, and we encouraged campers to share their projects with their family members. We believed and hoped that these camp design choices would foster conversations between parents about the child's interest in CS, and subsequently, would lead to increased perceptions of parental support. These findings suggest that camps designed to broaden participation in CS should find ways to integrate parental involvement into the curriculum.

\section{CONCLUSION, LIMITATIONS, AND FUTURE RESEARCH}

Although past research has found positive results for increasing middle schoolers' knowledge of CS concepts, there have been several studies that have reported mixed results in regard to student interest and affect towards CS. This study not only found a significant increase in middle schooler interest in CS, but also identified both mother and father support gains as significant predictors of gains in CS interest. Albeit, gains in father support only had a significant indirect effect on gains in CS interest. Furthermore, by looking at the interview data, we identified potential reasons for these relationships as well as some approaches for involving parents in their child's interest. These findings are encouraging given the current call for recruiting diverse groups of youth into CS fields. However, more research must continue to investigate other approaches for involving parents in the recruitment process. Furthermore, it is important to confirm that such approaches are in fact eliciting the hypothesized effects. Finally, it is also necessary to compare how parental support strategies affect children of different genders, which we hope to focus on in our future research on this project.

There were a few limitations that must be acknowledged for this study. First, we hypothesized that gains in mother and father support were a result of our campers returning home with an android device. However, we were unable to collect data from parents to confirm if this was a factor. Secondly, our sample sizes were not ideal for conducting path analyses, and thus, we were forced to create reduced models. It may have been that a more complicated model could better represent the relationship between parental support and CS interest. However given our sample size we were unable to test this. We plan to combine our current data with future data to further test some of these findings. 


\section{ACKNOWLEDGEMENTS}

This work was supported by a grant (\#1614849) from the National Science Foundation. Any opinions, findings, and conclusions or recommendations expressed in this paper are those of the authors and do not necessarily reflect the views of the National Science Foundation or Utah State University.

\section{REFERENCES}

[1] Annette E. Alliman-Brissett, Sherri L. Turner, and Thomas M. Skovholt. 2004. Parent support and African American adolescents' career self-efficacy. Professional School Counseling 7, 3 (2004), 124-133.

[2] Catherine Ashcraft, Elizabeth Eger, and Michelle Friend. 2012. Girls in IT: the facts. Technical Report. Boulder, CO

[3] Abdulkadir Bahar and Tufan Adiguzel. 2016. Analysis of Factors Influencing Interest in STEM Career : Comparison between American and Turkish High School ... Analysis of Factors Influencing Interest in STEM Career : Comparison between American and Turkish High School Students with High Ability. Journal of STEM Education 17, 3 (2016), 64-69.

[4] Bureau of Labor Statistics. 2015. Household Data. Technical Report. 1-10 pages. http://www.bls.gov/Cps/Cpsaat11.Pdf

[5] Cheryl Carrico and Chosang Tendhar. 2012. The Use of the Social Cognitive Career Theory to Predict Engineering Students' Motivation in the Produced Program. In ASEE Annual Conference and Exposition, Conference Proceedings, 119th ASEE Annual Conference and Exposition.

[6] Jody Clarke-Midura, Frederick Poole, Katarina Pantic, and Vicki Allan. 2017. Playing Mentor: A New Strategy for Recruiting Young Women into Computer Science. Fournal of Women and Minorities in Science and Engineering 23, 3 (2017).

[7] Jody Clarke-Midura, Frederick Poole, Katarina Pantic, Megan Hamilton, Chongning Sun, and Vicki Allan. 2018. How Near Peer Mentoring Affects Middle School Mentees. In Proceedings of the 49th ACM Technical Symposium on Computer Science Education. Baltimore, Maryland, USA, 664-669.

[8] Michael Cole. 1998. Cultural psychology: A once and future discipline. Harvard University Press.

[9] Jill Denner. 2011. What Predicts Middle School Girls' Interest in Computing? International fournal of Gender Science and Technology 3, 1 (2011), 53-59.

[10] Jacquelynne Eccles. 2009. Who am I and what am I going to do with my life? Personal and collective identities as motivators of action. Educational Psychologist 44, 2 (2009), 78-89.

[11] Jacquelynne S Eccles. 1994. Understanding women's educational and occupational choices: Applying the Eccles et al. Model of Achievement-Related Choices. Psychology of Women Quarterly 18 (1994), 585-609.

[12] Jacquelynne S. Eccles. 2015. Gendered Socialization of STEM Interests in the Family. International fournal of Gender, Science and Technology 7, 2 (2015), 116132.

[13] Jacquelynne S Eccles and Rena D Harold. 1993. Parent-school involvement during the early adolescent years. Teachers College Record 94, 3 (1993), 568-587. https://doi.org/0161-4681-93/9403/568\$1.25/0 arXiv:NIHMS150003

[14] Elizabeth Fennema and Julia A. Sherman. 2017. Mathematics Attitudes Scales : Instruments Designed to Measure Attitudes toward the Learning of Mathematics by Females and Males Author ( $\mathrm{s}$ ): Elizabeth Fennema and Julia A. Sherman Source : Journal for Research in Mathematics Education .. Journal for Research in Mathematics Education 7, 5 (2017), 324-326.

[15] Tamara R. Ferry, Nadya A. Fouad, and Philip L. Smith. 2000. The Role of Family Context in a Social Cognitive Model for Career-Related Choice Behavior: A Math and Science Perspective. Fournal of Vocational Behavior 57, 3 (2000), 348-364. https://doi.org/10.1006/jvbe.1999.1743

[16] Deborah Fields, Lisa Quirke, Tori Horton, Jason Maughan, Xavier Velasquez, Janell Amely, and Katarina Pantic. 2016. Working toward equity in a construc tionist Scratch camp: Lessons learned in applying a studio design model. In Constructionism in Action, Arnan Sipitakiat and Nalin Tutiyaphuengprasert (Eds.) Bangkok, Thailand, 291-298.

[17] Janet L. Gates. 2002. Women's career influences in traditional and nontraditional fields. Technical Report.

[18] Shuchi Grover, Roy Pea, and Stephen Cooper. 2015. Designing for deeper learning in a blended computer science course for middle school students. Computer Science Education 25, 2 (2015), 199-237. https://doi.org/10.1080/08993408.2015. 1033142

[19] Judith M. Harackiewicz, Christopher S. Rozek, Chris S. Hulleman, and Janet S. Hyde. 2012. Helping Parents to Motivate Adolescents in Mathematics and Science An Experimental Test of a Utility-Value Intervention. Psychological Science 23, 8 (2012), 899-906. https://doi.org/10.1177/0956797611435530

[20] Nancy E. Hill and Ming Te Wang. 2015. From middle school to college: Developing aspirations, promoting engagement, and indirect pathways from parenting to post high school enrollment. Developmental Psychology 51, 2 (2015), 224-235. https://doi.org/10.1037/a0038367

[21] Yingdan Huang, Jane Meyers, Wendy Dubow, Zhen Wu, and Michael Eisenberg. 2013. Ubiquitous and Mobile Learning in the Digital Age. In Ubiquitous and Mobile Learning in the Digital Age, Demetrios G. Sampson, Pedro Isaias, Dirk Ifenthaler, and Michael Spector (Eds.). Springer-Verlag New York, New York, NY, 215-226. https://doi.org/10.1007/978-1-4614-3329-3

[22] Kathleen M. Jodl, Alice Michael, Oksana Malanchuk, Jacquelynne S. Eccles, and Arnold Sameroff. 2001. Parents' Roles in Shaping Early Adolescents' Occupational Aspirations. Child Development 72, 4 (2001), 1247-1266. https://doi.org/10.1111/ 1467-8624.00345

[23] Ciltlin Kelleher and Randy Pausch. 2007. Using storytelling to motivate programming. COMMUNICATIONS OF THE ACM 50, 7 (2007), 59-64.

[24] Jordana Kerr, Mary Chou, Reilly Ellis, and Caitlin Kelleher. 2013. Setting the scene: Scaffolding stories to benefit middle school students learning to program. In 2013 IEEE Symposium on Visual Languages and Human Centric Computing. 95-98. https://doi.org/10.1109/VLHCC.2013.6645250

[25] D Midian Kurland and Roy D Pea. 1985. Children's mental models of recursive LOGO programs. Fournal of Educational Computing Research 1, 2 (1985), 235-243.

[26] John Maloney, Kylie Peppler, Yasmin B. Kafai, Mitchel Resnick, and Natalie Rusk. 2008. Programming by choice: urban youth learning programming with scratch. In Proceedings of the 39th SIGCSE technical symposium on Computer science education. Portland, OR, USA, 367-371. https://doi.org/10.1145/1352135.1352260

[27] Christine McLachlan, Annemieke Craig, and Jo Coldwell. 2010. Student perceptions of ICT: A gendered analysis. In Proceedings of the Twelfth Australasian Conference on Computing Education, Vol. 103. Brisbane, Australia, 127-136.

[28] Orni Meerbaum-Salant, Michal Armoni, and Mordechai (Moti) Ben-Ari. 2013. Learning computer science concepts with Scratch. Computer Science Education 23, 3 (2013), 239-264. https://doi.org/10.1080/08993408.2013.832022

[29] Chrystalla Mouza, Alison Marzocchi, Yi Cheng Pan, and Lori Pollock. 2016. Development, implementation, and outcomes of an equitable computer science after-school program: Findings from middle-school students. Journal of Research on Technology in Education 48, 2 (2016), 84-104. https://doi.org/10.1080/15391523. 2016.1146561

[30] National Science Foundation. 2017. Women, minorities, and persons with disabilities in science and engineering: 2017 Report. Technical Report. 1-21 pages. https://doi.org/SpecialReportNSF17-310

[31] Luther B Otto. 2000. Youth Perspectives on Parental Career Influence. Fournal of Career Development 27, 2 (2000), 111-118.

[32] Sylvia Palmer and Larry Cochran. 1988. Parents as Agents of Career Development. Journal of Counseling Psychology 35, 1 (1988), 71-76. https://doi.org/10.1037/ 0022-0167.35.1.71

[33] Ramona Palos and Loredana Drobot. 2010. The impact of family influence on the career choice of adolescents. Procedia - Social and Behavioral Sciences 2, 2 (2010), 3407-3411. https://doi.org/10.1016/j.sbspro.2010.03.524

[34] Katarina Pantic, Deborah A. Fields, and Lisa Quirke. 2016. Studying situated learning in a constructionist programming camp. In Proceedings of the The 15th International Conference on Interaction Design and Children. Manchester, UK, 428-439. https://doi.org/10.1145/2930674.2930725

[35] R Core Team. 2016. R: A Language and Environment for Statistical Computing. $\mathrm{R}$ Foundation for Statistical Computing, Vienna, Austria. https://www.R-project. org/

[36] Simon Lloyd D. Restubog, Afryll R. Florentino, and Patrick Raymund James M. Garcia. 2010. The mediating roles of career self-efficacy and career decidedness in the relationship between contextual support and persistence. Fournal of Vocational Behavior 77, 2 (2010), 186-195. https://doi.org/10.1016/j.jvb.2010.06.005

[37] Jacqueline C. Simpson. 2003. Mom matters: Maternal influence on the choice of academic major. Sex Roles 48, 9-10 (2003), 447-460. https://doi.org/10.1023/A: 1023530612699

[38] Sherri Turner and Richard T. Lapan. 2002. Career self-efficacy and perceptions of parent support in adolescent career development. (2002), 44-55 pages. https: //doi.org/10.1002/j.2161-0045.2002.tb00591.x

[39] Ioanna Vekiri and Anna Chronaki. 2008. Gender issues in technology use: Perceived social support, computer self-efficacy and value beliefs, and computer use beyond school. Computers and Education 51, 3 (2008), 1392-1404. https://doi.org/10.1016/j.compedu.2008.01.003

[40] Allan Wigfield and Jacquelynne S Eccles. 2000. Expectancy-value theory of achievement motivation. Contemporary educational psychology 25, 1 (2000), 68-81. 